Check for updates

Cite this: RSC Adv., 2018, 8, 4610

Received 28th September 2017

Accepted 4th January 2018

DOI: $10.1039 / c 7 r a 10745 e$

rsc.li/rsc-advances

\section{The effect of MDI on the structure and mechanical properties of poly(lactic acid) and poly(butylene adipate-co-butylene terephthalate) blends}

\author{
Hongwei Pan, ${ }^{\text {ab }}$ Zonglin $\mathrm{Li}^{\text {ab }}$ Jia Yang, ${ }^{\mathrm{c}}$ Xin $\mathrm{Li}^{\mathrm{c}}{ }^{\mathrm{C}}$ Xue $\mathrm{Ai}^{\mathrm{d}}{ }^{\text {Y Yanping Hao, }}{ }^{\mathrm{a}}$ \\ Huiliang Zhang (iD *a and Lisong Dong ${ }^{a}$
}

In this work, poly(lactic acid) and poly(butylene adipate-co-terephthalate) (PLA/PBAT 50/50) were meltblended in the presence of $4,4^{\prime}$-methylene diphenyl disocyanate (MDI) which acted as a reactive chain extender. The mechanical properties, phase morphology, thermal behavior and crystalline structure of the blends were investigated. Fourier transform infrared measurements revealed that some remarkable chemical interaction had taken place between the two polymers and MDI. Upon increasing the content of $\mathrm{MDI}$, the blends showed increased tensile strength and elongation at break. With the addition of $0-$ $2 \mathrm{wt} \% \mathrm{MDI}$, the impact strength of PLA/PBAT-MDI blends increased from $7.0 \mathrm{~kJ} \mathrm{~m}^{-2}$ to $70.0 \mathrm{~kJ} \mathrm{~m}^{-2}$. A large shift towards each other in terms of the glass transition temperature was observed by DMA and DSC analysis. SEM micrographs showed not only a reduction in the PBAT phase size but also a significant increase in interfacial adhesion between the PLA and PBAT phases with increasing of MDI. Furthermore, the toughening mechanism of the oriented samples was confirmed by wide-angle $X$-ray diffraction (WAXD) and small-angle X-ray scattering (SAXS) images; it was possible for the smaller crystallites of blends to form during the course of chain extension.

\section{Introduction}

Among bio-sourced polymers, poly(lactic acid) (PLA) is a linear aliphatic polyester which can be produced from the renewable biomass such as corn, and it is also biodegradable in the ambient environment. ${ }^{\mathbf{1} 2}$ Extensive works related to PLA synthesis, chemical, physicochemical and mechanical properties have been performed. However, low degradation rate, relatively high cost and high inherent brittleness are considered as limitations for its applications. Blending PLA with other polymers is one of the several methods to overcome the aforementioned limitations. The toughening modification of PLA has been extensively investigated, such as copolymerizing lactides with other monomers or macromolecules, and blending PLA with flexible polymers or plasticizers to obtain flexible PLAbased copolymers. ${ }^{3}$ The biodegradable aliphatic polyesters used for toughening PLA mainly include polypropylene carbonate (PPC), ${ }^{2,4-6}$ poly(butylene adipate-co-terephthalate) (PBAT), ${ }^{7-10}$ poly( $\varepsilon$-caprolactone) (PCL), ${ }^{11,12}$ polyamide 11 (PA11). ${ }^{13}$ poly

\footnotetext{
${ }^{a}$ Key Laboratory of Polymer Ecomaterials, Chinese Academy of Sciences, Changchun Institute of Applied Chemistry, Changchun 130022, China. E-mail: hlzhang@ciac.ac. cn; Tel: +86-431-85262689

${ }^{b}$ University of Chinese Academy of Sciences, Beijing, 10080, China ${ }^{c}$ Changchun University of Technology, Changchun 130012, China

${ }^{d}$ College of Chemical and Environmental Engineering, Shandong University of Science and Technology, Qingdao 266510, China
}

(butylene-succinate-co-adipate) (PBSA) ${ }^{\mathbf{1 4}}$ poly(butylenes succinate) (PBS), ${ }^{15,16}$ poly[(ethylene oxide)-block-(amide-12)](PEBA), ${ }^{17-19}$ etc.

Compared with copolymerization, blending modification of PLA is more economical and more suitable for industrialized production. However, most of these blends are immiscible. A chain extender is used to modify and improve the properties of the immiscible polymer, not only the intrinsic properties of the blend components, but also the control of the dispersed phase diameter. The final properties of the blend can be affected profoundly.

Macroscopic deformation behavior and physical properties of immiscible heterogeneous polymer blends may be enhanced by compatibilization through the introduction of physical or (and) chemical interactions between the components. ${ }^{20}$ The presence of functional groups in polymer chains, giving rise to specific interactions with the blend constituent, can enhance the interfacial adhesion and phase dispersion, and improve the overall characteristics of the systems. ${ }^{21}$

Poly(butylene adipate-co-terephthalate), a copolymer of butylene adipate (BA) and butylene terephthalate (BT) characterized as an ideal random copolymer with a molar ratio of aliphatic to aromatic units around $1: 1,{ }^{22}$ has been studied more extensively due to its compatibility with PLA, high elongation at break, high impact strength and biodegradability. Concerning the PBAT polymer, it was reported that the introduction of aromatic polyester into the backbone chain of 
aliphatic polyester improved both the mechanical properties and the melt strength. Moreover, the crystallization phenomena of the two polymers were disparate.

The earlier attempt has shown that PBAT effectively increased the impact strength of PLA in melting process. ${ }^{23}$ Nevertheless, the compatibility is not sufficient due to the poor interactions and poor interfacial adhesion at a molecular level which lead to non-thermodynamically stable morphologies after mixing. ${ }^{24,25}$ Recently, the PLA/PBAT blends containing two crystalline components have been investigated and documented in the literature. A challenge exists for the immiscible is the phase-separated morphology, which leads to deterioration of desirable properties. Zhou et al. reported the miscibility and crystallization behavior of PBAT and PLA blends. They investigated that the synergetic function of elongational flow field and "chain mobility promoter" could efficaciously promote the motion of PLA molecular chain to develop oriented crystalline architecture, and elongational flow field could deform the dispersed phase PBAT into nanofibrils featuring large specific surface area to perfect the phase interface. ${ }^{26}$ Dil et al. studied the morphology and miscibility of PLA and PBAT blends in detail, the dispersed PBAT phase diameter showed a significant increase in diameter with incorporate minor phase concentration, but more a result of the partial miscibility phenomenon, and the continuous and co-continuous morphology development in polymer blends with different types of the interfaces showed a highly interacting. ${ }^{27}$ The results of these studies clearly indicate that the level of interaction between components in low interfacial tension polymer blends and their mutual miscibility/immiscibility can have a determining effect on the morphology development.

Recently, additives called chain extenders as well as compatibilizers in polymer blends have been developed to improve melt strength, thermal stability in polymer blends. ${ }^{28}$ Al-Itry et al. ${ }^{29-32}$ demonstrated that incorporation of a chain extender lead to an improvement of the melt strength and a better compatibilization for PLA/PBAT blends. In order to enhance the in situ compatibilization, crosslinking was also introduced in the work by adding triallyl isocyanurate (TAIC), dicumyl peroxide (DCP), and 4,4'-methylene diphenyl diisocyanate (MDI). MDI is one of the chain extenders widely used in two component systems based on reactive polyurethane chemistry because it contains two isocyanate groups, and it has highly reactive to carboxyl and hydroxyl groups, thus MDI was employed to improve the interfacial compatibility. ${ }^{33}$ The isocyanate groups readily react with the hydroxyl and carboxylic acid groups to form urethane groups. Li et al. ${ }^{34}$ have studied that the thermal and mechanical performance of PLA can be increased by reacting with MDI at an appropriate portion. Zhao et al. ${ }^{35}$ used MDI to improve the compatibility of PLA and TPU phases, and decreased the dispersed TPU phase size. Wang et al. ${ }^{36,37}$ approved that the MDI appeared to function as a coupling agent, improved the interfacial interaction, and consequently, enhanced the mechanical properties of the PLA and starch blends.

In this study, the biodegradable PLA/PBAT blends were prepared by melt compounding using chain extenders to enhance in compatibilization. This study explained the question of the influence of a crystalline phase on the tensile drawing behavior and the strain-induced structural changes in PLA and PBAT. The phase morphologies and crystallization behaviors of PLA/PBAT-MDI blends were examined by using SEM, WAXD, and SAXS. The purpose of the present study is to understand the miscibility and crystallization behavior in the crystalline polymer blends. It was expected that chain extension technology would be effective in improving the properties of the immiscible polymer and consequently expanding the utilization of PLA and PBAT.

\section{Experimental}

\subsection{Material and sample preparation}

2.1.1. Material. The PLA (Grade 4032D) used in this work was a commercially available product from Natureworks LLC (USA). It exhibited a weight-average molecular weight of $2.07 \times$ $10^{5} \mathrm{~g} \mathrm{~mol}^{-1}$ and polydispersity of 1.74 as determined by gel permeation chromatography (GPC). PBAT (Ecoflex FBX 1200), was supplied by BASF Corporation (Germany). PBAT (45\% BA$c o-55 \% \mathrm{BT}$ ) with a melt flow index of 3.3-6.6 g per $10 \mathrm{~min}$ (at $190{ }^{\circ} \mathrm{C}, 2.16 \mathrm{~kg}$ ), density of $1.25-1.27 \mathrm{~g} \mathrm{~cm}^{-3}$, the molecular weight of $1.42 \times 10^{5} \mathrm{~g} \mathrm{~mol}^{-1}$, the glass transition temperature $\left(T_{\mathrm{g}}\right)$ of -25 to $-30{ }^{\circ} \mathrm{C}$, the melting point of $115-120{ }^{\circ} \mathrm{C} .4,4^{\prime}-$ Methylene diphenyl diisocyanate (MDI) produced by Aladdin Industrial Corporation, China, has a melting point of $38-42{ }^{\circ} \mathrm{C}$ and a boiling point of $200{ }^{\circ} \mathrm{C}$ at $700 \mathrm{~Pa}$.

2.1.2. Processing and blend preparation. Both PLA and PBAT were dried in a vacuum oven at $80^{\circ} \mathrm{C}$ for $24 \mathrm{~h}$. Then dried PLA and PBAT (50 wt/50 wt) as well as the MDI were dry mixed thoroughly and used a Haake batch intensive mixer (Haake Rheo-mix 600, Karlsruhe, Germany) with a batch volume of $50 \mathrm{~mL}$ at various MDI contents. The melt compounding was performed at $180^{\circ} \mathrm{C}$ for $10 \mathrm{~min}$, and the rotor speed was $60 \mathrm{rpm}$. The mixing compositions of the PLA/PBAT-MDI blended with $0 \mathrm{wt} \%, 0.5 \mathrm{wt} \%, 1.0 \mathrm{wt} \%, 1.5 \mathrm{wt} \%$ and $2.0 \mathrm{wt} \% \mathrm{MDI}$, respectively. After mixing, all the samples were cut into small pieces and then hot-pressed at $190{ }^{\circ} \mathrm{C}$ for $5 \mathrm{~min}$, followed by cold pressing at room temperature to form sheets with various thicknesses for characterization. Dumbbell-shaped amorphous sample bars with dimensions of $20 \mathrm{~mm} \times 4 \mathrm{~mm} \times 1 \mathrm{~mm}$ were cut from the blends sheet for in situ structure determination during stretching, and then stretched at a drawing rate of 100 $\mathrm{mm} \min ^{-1}$ by using a 1121 testing machine (Instron Corporation, USA), which could draw the bar symmetrically so that the incident beam could illuminate the same position of the sample.

\subsection{Characterization and measurements}

2.2.1. Fourier transform infrared spectroscopy (FTIR). Chemical structures of modified PLA and modified PBAT were examined using a Fourier transform infrared spectroscopy (Bruker, Vertex 70) over the wavenumbers ranging from 4000 to $400 \mathrm{~cm}^{-1}$. The samples PLA-MDI and PBAT-MDI were extracted by Soxhlet extraction in tetrahydrofuran for 12 hours. The 
sample for the FTIR experiment was prepared by a $\mathrm{KBr}$ disk method.

2.2.2. Rheological properties. Rheological measurements of the PLA/PBAT-MDI blends were conducted with a Physica MCR 2000 rheometer (AR 2000ex USA) at $200{ }^{\circ} \mathrm{C}$. Frequency sweep for the sample was carried out using $25 \mathrm{~mm}$ plate-plate geometry. The gap distance between the parallel plates was $0.9 \mathrm{~mm}$ for all tests. The sheet samples were about $1.0 \mathrm{~mm}$ in thickness. A strain sweep test was initially conducted to determine the linear viscoelastic region of the materials. The angular frequency range used during testing was 0.1-100 $\mathrm{rad} \mathrm{s}^{-1}$.

2.2.3. Mechanical properties. The uniaxial tensile tests were carried out at room temperature on an 1121 testing machine (Instron Corporation, USA), which could draw the bar symmetrically so that the incident beam could illuminate the same position of the sample. Specimens $(20 \mathrm{~mm} \times 4 \mathrm{~mm} \times 1$ $\mathrm{mm}$ ) were cut from the previously compression-molded sheet into a dumbbell shape. The measurements were conducted at a cross-head speed of $100 \mathrm{~mm} \mathrm{~min}^{-1}$ at $23 \pm 2{ }^{\circ} \mathrm{C}$ according to ASTM D638-2008. At least five runs for each sample was measured, and the results were averaged. Notched Izod impact tests were performed at $23 \pm 2{ }^{\circ} \mathrm{C}$ according to ASTM D256-2010 on an impact testing machine (CEAST, Chengde, China). The samples with dimensions $80 \mathrm{~mm} \times 10 \mathrm{~mm} \times 3 \mathrm{~mm}$ were obtained from compression-molded specimens. The notch was milled in having a depth of $2.54 \mathrm{~mm}$, an angle of $45^{\circ}$, and a notch radius of $0.25 \mathrm{~mm}$.

2.2.4. Dynamic mechanical analysis (DMA). Characterization of thermal mechanical properties of pure PLA, pure PBAT, and PLA/PBAT-MDI blends were performed with TA Instruments' DMA Q800 Dynamic Mechanical Analyzer (USA) using a $10 \mathrm{~mm} \times 4 \mathrm{~mm} \times 1 \mathrm{~mm}$ sample. The experiment was carried out in tension mode at a constant heating rate of $3{ }^{\circ} \mathrm{C} \mathrm{min}^{-1}$, from -60 to $120^{\circ} \mathrm{C}$. The deformation amplitude and frequency were set at $15 \mu \mathrm{m}$ and $1 \mathrm{~Hz}$, respectively.

2.2.5. Differential scanning calorimetry (DSC). Thermal properties of the samples were measured by using DSC (TA Instruments DSC Q20 USA). The sample weights were between 5 and $8 \mathrm{mg}$. First, samples were equilibrated at $-60^{\circ} \mathrm{C}$, and then heated at a rate of $10^{\circ} \mathrm{C} \mathrm{min}^{-1}$ from -60 to $190{ }^{\circ} \mathrm{C}$. In the first run, the thermal history of the sample was erased. It was then cooled down to $-60{ }^{\circ} \mathrm{C}$ at a cooling rate of $10{ }^{\circ} \mathrm{C} \mathrm{min}^{-1}$. Subsequently, a second heating scan to $190^{\circ} \mathrm{C}$ was conducted at the same heating rate. The degree of crystallinity of the samples was evaluated from the heat evolved during crystallization by the following relationship:

$$
\chi_{\mathfrak{c}}(\%)=\frac{\Delta H_{f}}{W \times \Delta H_{f}^{\circ}} \times 100
$$

where $\chi_{c}$ is the degree of crystallinity of the PLA or PBAT, " $\Delta H_{f}$ " is the measured heat of fusion, " $f$ " is the weight fraction of PLA or PBAT in the blends and " $\Delta H_{f}^{\circ}$ " is the enthalpy of fusion for a crystal having infinite crystal thickness $\left(93 \mathrm{~J} \mathrm{~g}^{-1}\right.$ for PLA and $114 \mathrm{~J} \mathrm{~g}^{-1}$ for PBAT). ${ }^{38}$

2.2.6. Scanning electron microscopy (SEM). The cryofracture surfaces of PLA/PBAT-MDI blends were the object of the morphological analysis characterized by scanning electron microscope (model Japan JXA-840 ESEMFE) at an accelerating voltage of $5 \mathrm{kV}$. The fractured surfaces for the analysis was achieved by cryo-fracturing the blends in liquid nitrogen and then covering with a thin layer of gold.

2.2.7. Wide angle X-ray diffraction (WAXD) and small angle X-ray scattering (SAXS). To investigate the effect of the stretching process on the mechanical properties of the drawn PLA/ PBAT-MDI blends, stretching experiments were carried out using a tensile-testing machine. The blends were stretched with a stretching rate of $100 \mathrm{~mm} \mathrm{~min}^{-1}$ at room temperature.

Wide angle X-ray diffraction experiments of blends were performed on a D8 advance X-ray diffractometer (Bruker, Germany) at room temperature in the range of $5-55^{\circ}$ at a scanning rate of $4^{\circ} \mathrm{min}^{-1}$. The $\mathrm{Cu} \mathrm{K}_{\alpha}$ radiation $(\lambda=0.15418 \mathrm{~nm})$ source was operated at $40 \mathrm{kV}$ and $200 \mathrm{~mA}$.

The apparent crystal size (ACS) of PLA/PBAT blends was estimated by Scherrer's eqn (2) and (3): ${ }^{39}$

$$
\mathrm{ACS}=\frac{K \lambda}{\beta_{h k l} \cos \theta_{h k l}}
$$
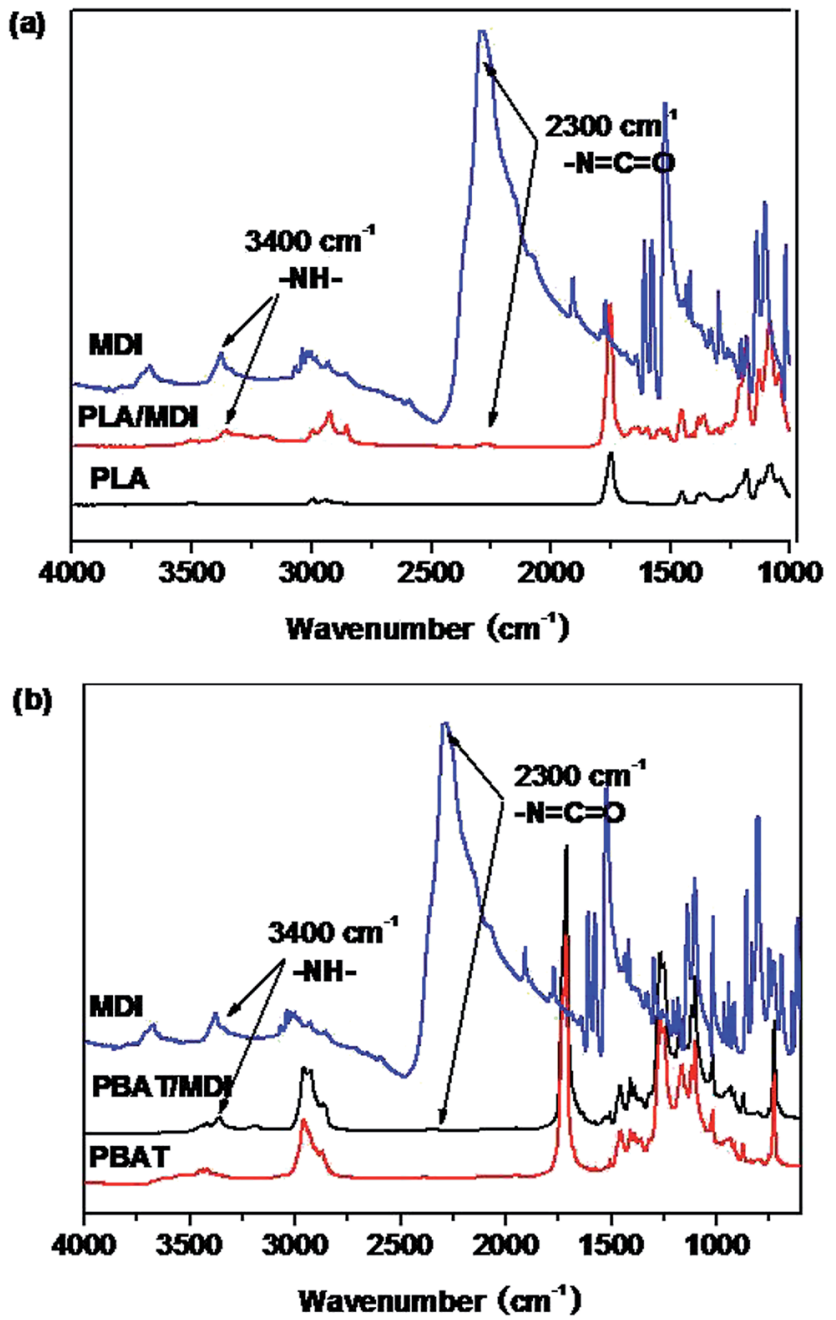

Fig. 1 The FTIR spectrum of the PLA (a) and the PBAT (b) chain branched with MDI. 
with

$$
\beta=\left(B^{2}-b^{2}\right)^{1 / 2}
$$

where $K$ is the Scherrer constant takes a value of $0.9, \lambda$ is the wavelength of the X-ray (1.5418 $\AA$ ) and $\theta$ is the Bragg angle. $B$ is the half width in radians of the diffraction angle of the (011), (010), (110), (100), and (111), and $b$ is the instrumental constant $\left(0.1^{\circ}\right)$. The calculated values of ACS are listed in Table 3 .

In situ synchrotron SAXS measurements were performed at the beamline 1W2A at BSRF, Beijing, China, with the wavelength of synchrotron X-ray radiation being $0.154 \mathrm{~nm}$. At this distance the effective scattering vector $q(q=(4 \pi \sin \theta) / \lambda$, where $2 \theta$ is the scattering angle and $\lambda$ is the wavelength) range is $0.20-$ $1.60 \mathrm{~nm}^{-1}$. The X-ray exposure time was $60 \mathrm{~min}$. Here, $I$ is the experimental SAXS intensity. The long spacing $\left(d_{\mathrm{ac}}\right)$, which was defined as the crystal layer thickness together with one interlamellar amorphous layer, measured along the lamella normal and calculated using Bragg eqn (4). ${ }^{40}$ The crystal layer thickness $d_{\mathrm{c}}$ and the amorphous layer thickness $d_{\mathrm{a}}$ can be calculated using eqn (5) and (6), respectively.

$$
\begin{gathered}
L(\mathrm{~nm})=\frac{2 \pi}{q_{\mathrm{max}}} \\
d_{\mathrm{c}}=d_{\mathrm{ac}} \times X_{\mathrm{c}, 2} \\
d_{\mathrm{a}}=d_{\mathrm{ac}}-d_{\mathrm{c}}
\end{gathered}
$$

\section{Results and discussion}

\subsection{Fourier transform infrared spectroscopy analysis}

Fig. 1 shows the FTIR spectra of the PLA/MDI and PBAT/MDI blends. Both PLA and PBAT can form branched and/or crosslinked structures with chain extender as shown in Scheme 1. As a consequence, complex reaction products could be obtained, including branched PLA, branched PBAT and PLA-crosslinkPBAT network. It was suggested that diisocyanate can connect the hydroxyl end groups of PLA and PBAT molecules through urethane bonds as shown in reaction of Scheme 1 . The $\mathrm{N}-\mathrm{H}$ absorption peak appeared at $3400 \mathrm{~cm}^{-1}$, the stretching band corresponding to the isocyanate group was not found at $2270 \mathrm{~cm}^{-1}$, indicating that the initial isocyanate groups completely reacted with the PLA and PBAT. The sharp absorption peaks around $1730-1700 \mathrm{~cm}^{-1}$ are typical for the stretching vibration of esters $\mathrm{C}=\mathrm{O}$, the $1220 \mathrm{~cm}^{-1}$ absorption peak caused by the vibration of $\mathrm{C}=\mathrm{C}$ in benzene ring. As in the Scheme 1 shows the chain extension reaction of free radicals.

\subsection{Rheological properties}

Fig. 2 shows the rheological test results of the plate and rotor from a dynamic frequency sweep test of the two polymers. Master curves of $G^{\prime}$ and $\left|\eta^{*}\right|$ at a reference temperature of $200{ }^{\circ} \mathrm{C}$ were built using the time-temperature superposition principle. The PBAT could enhance the elasticity of PLA, and improve largely its melt strength. The $G^{\prime}$ of the PLA/PBAT-MDI blends showed special viscoelastic relaxation behavior and exhibited a distinct plateau at low frequencies. With the addition of 1.0 to
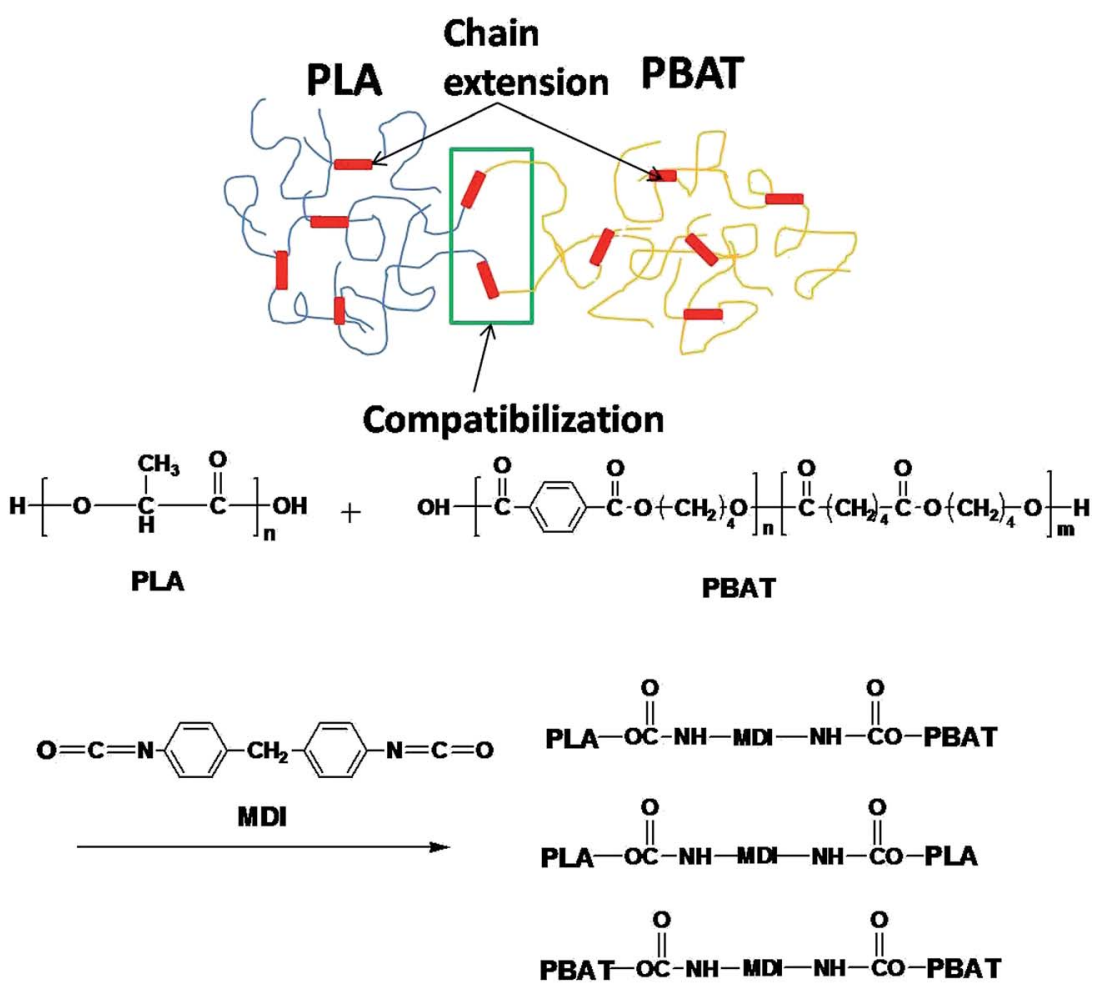

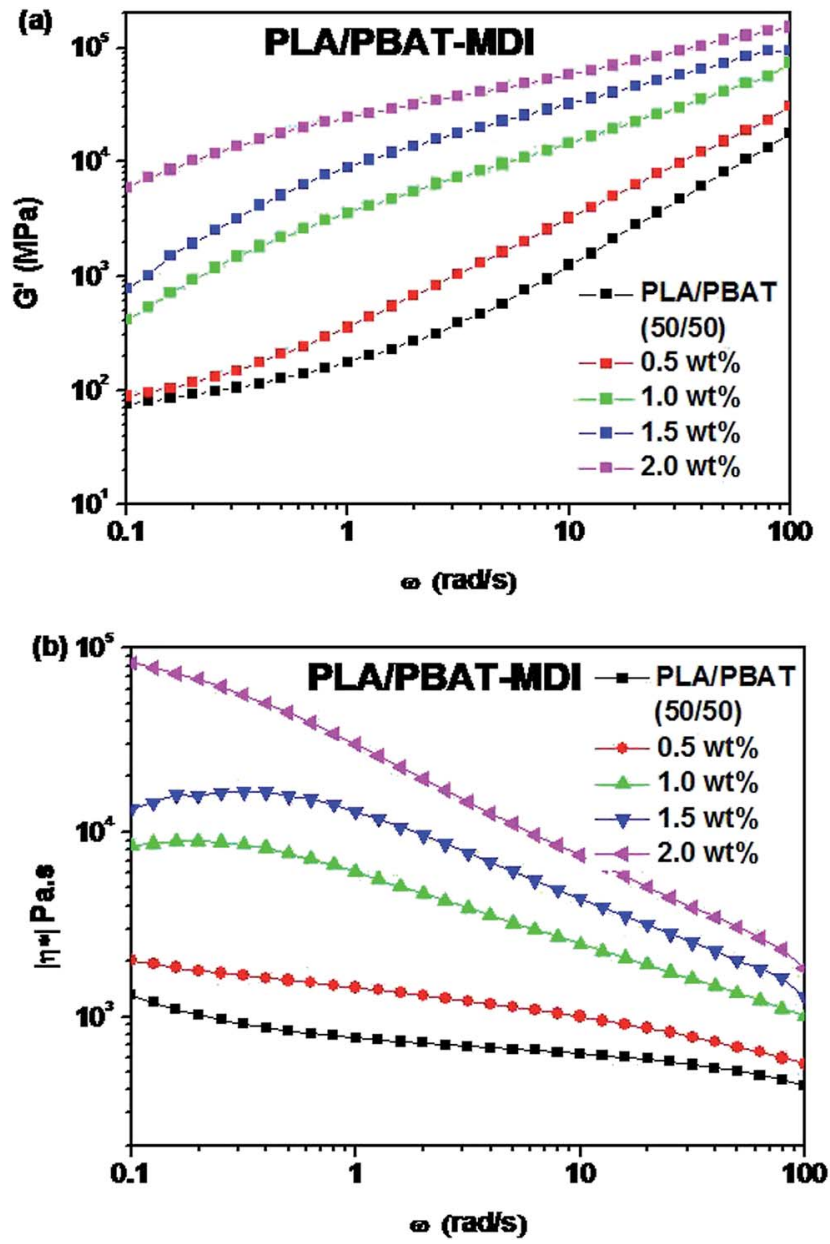

Fig. 2 Rheological behaviors of PLA/PBAT-MDI blends: (a) storage modulus $\left(G^{\prime}\right)$, (b) complex viscosity $(|\eta *|)$.

$2.0 \mathrm{wt} \% \mathrm{MDI}$, the $G^{\prime}$ slopes of the blends increased at low frequencies. These results revealed that the compatibility behavior of MDI enhanced the interaction in the blends and promoted formation of the network structure. With the addition of MDI, it was worth noting that $\left|\eta^{*}\right|$ of the PLA/PBAT-MDI samples increased at all frequency. However, a decreasing complex viscosity is observed with the frequency increases. These changes indicated that the addition of MDI greatly increased the molecular interactions of the blend, and the movement of molecular chains was hindered remarkably due to the chain extension. It is because isocyanate group in the MDI molecules form $\mathrm{N}-\mathrm{H}$ bonds with the oxygen atoms of PLA and PBAT, so that the elasticity and viscosity of the blends increase simultaneously.

\subsection{Mechanical properties}

A tensile deformation test was performed to assess the extent of mechanical reinforcement with the incorporation of chain extender into polymers. Typical stress-strain curves of PLA/ PBAT-MDI blend are shown in Fig. 3, it shows the tensile strength and elongation at break of pure PLA, pure PBAT, and the PLA/PBAT-MDI blends in the presence of various MDI. PLA

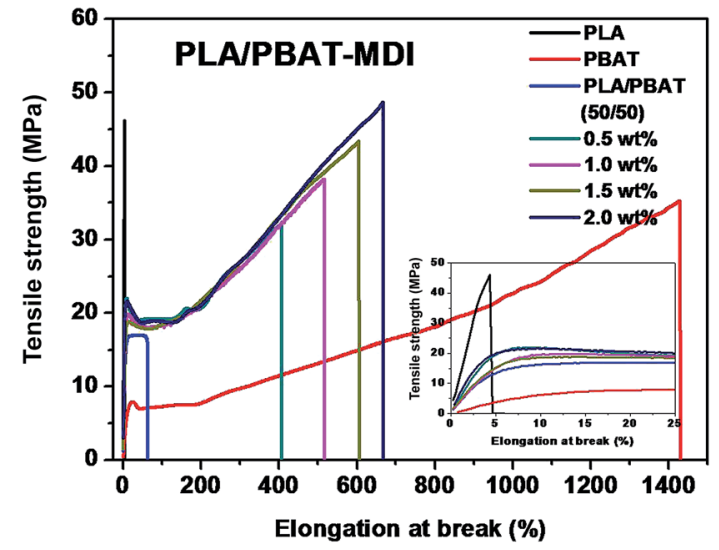

Fig. 3 Stress-strain curves of the drawn PLA/PBAT-MDI blends sample.

is very rigid and brittle with tensile strength near $46.4 \mathrm{MPa}$ and elongation at break only $4.7 \%$. The results showed that the brittle properties of PLA can be modified by the addition of PBAT. Compared with other mechanical properties of PLA/ PBAT-MDI blends, the elongation at break is more sensitive to the compatibilization effect in immiscible binary blends. It can be observed the evolution of the stress-strain curves, the tensile strength and elongation at break increases from 17.0 to $48.8 \mathrm{MPa}$ and from 62 to $663 \%$ with increasing the MDI content, respectively. With the increase of MDI, enhanced interfacial adhesion and higher molecular weight of PLA and PBAT would be obtained, thus resulting in gradually higher tensile strength and elongation at break.

PLA is very rigid at room temperature and shows low impact strength, while its modulus and tensile strength are comparatively high. ${ }^{41}$ Fig. 4 shows the notched Izod impact strength of the PLA/PBAT-MDI blends. As included in the figure, poor compatibility between PLA/PBAT phases, the poor interfacial adhesion due to the thermodynamic immiscibility of the two components resulted in a co-continuous phase morphology,

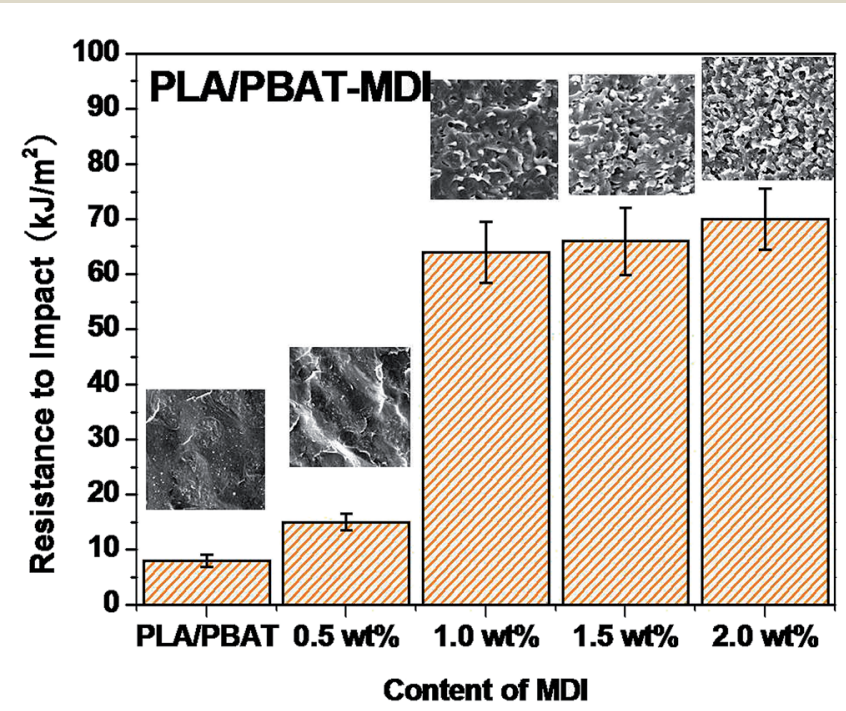

Fig. 4 Impact strength of the PLA/PBAT-MDI blends. 
thus reducing the impact strength. There was an increase in resistance to impact when MDI added to PLA/PBAT (50/50) phase, the impact strength increased from 7 to $70.0 \mathrm{~kJ} \mathrm{~m}^{-2}$. As such, even though the two polymers are immiscible, the extent of some chains from both polymers intermingling at the interface would be maximal for the PLA/PBAT-MDI blends. From the Scheme 1, these intermingled chains at the interface acted as the bridge between the PLA and PBAT phases. ${ }^{42}$ In the compatibilized blends, greater applied energy is consumed for the above-mentioned processes, volume dilation, void initiation and propagation, hence more toughening is obtained compared to that of the neat blend. ${ }^{43}$ This observation is an indication of the role of improved interfacial adhesion in the enhancement of both impact and tensile toughness. The main reason is the addition of MDI, the branch structure formed, which restricted the mobility of the polymer chains to dissipate energy under a tensile load.

\subsection{Miscibility and SEM micrographs analysis}

The morphology and glass transition temperatures of the blends provide information on miscibility of PLA and PBAT. To further investigate the toughening mechanism of PLA/PBATMDI blends, the morphology of different necking regions of the tensile specimen was cryo-fractured longitudinally to verify the interfacial adhesion effect on the micromechanical deformation processes. ${ }^{44}$ The cryo-fractured surface morphology of

(a)

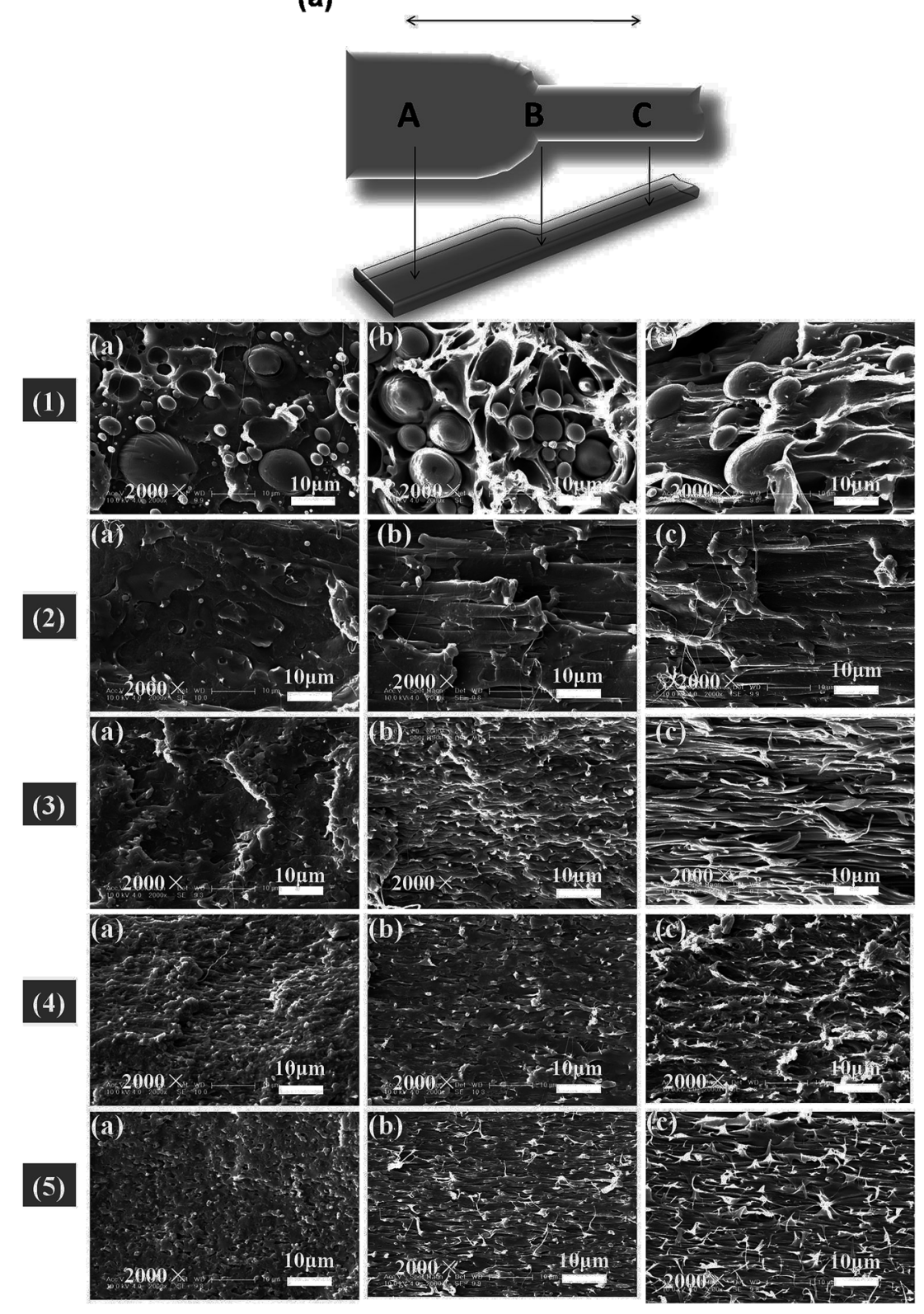

Fig. 5 Schematic diagram of the measurement locations $A, B$ and $C$ of the SEM micrographs of the PLA/PBAT-MDI blends during the tensile testing; (a) morphology in region $A$; (b) morphology in region $B$; (c) morphology in region C; PLA/PBAT-MDI samples: (1) PLA/PBAT (50/50), (2) $0.5 w t \%$, (3) $1.0 w t \%$, (4) $1.5 w t \%$ and (5) $2.0 w t \%$. 
the stretched PLA/PBAT-MDI blends was analyzed by using SEM in Fig. 5. It could be seen that the dispersed PBAT were spherical. The total surface area exposed by the droplets per volumetric space of the PLA/PBAT blend is shown in the Fig. 5(1). The initial droplets size, the polymer elasticity, the dispersed phase percentage and the draw ratio are the main factors affecting the morphology formed during drawing. Dil et al. used the AFM and SEM to observe the surface of PLA/PBAT blend, they also found the dispersed phase PBAT droplets were in a flat plane surface in the image. ${ }^{27}$ When the dispersed phase concentration gets to $1: 1$, complex structures, such as platelet, ribbon- or sheet-like, stratified and co-continuous structures, are formed..$^{45}$ As seen in Fig. 5[1(a-c)], PBAT with a size of approximately $10 \mu \mathrm{m}$ shows almost no wetting with the PLA phase indicating very low compatibility. For the neat PLA/PBAT blend, there are smoothly debonded surfaces, indicating complete phase separation, hence, brittle fracture. The PBAT phase size of the blends by reactive blending was much less than that by physical blending. The intermolecular reactions between PLA and PBAT resulted in forming a microstructure of PLA-crosslink-PBAT copolymers, which improved their compatibility, and thus decreasing the size of PBAT phase. The phase separation in the blends is further corroborated by DMA results. The curves of $\tan \delta$ plot show that neat PLA is featured by a single peak at $63.7^{\circ} \mathrm{C}$ related to the glass transition, where as that of neat PBAT shows to a broad peak, at $-25{ }^{\circ} \mathrm{C}$, corresponding to the glass transitions in the aliphatic-rich amorphous phase in Fig. 6(a). The presence of these two peaks confirms the phase separation in the blends. However, after adding MDI, the PLA/PBAT-MDI blends show different behaviors and the different deformation stages during stretching are presented in Fig. 5[1(b)-5(b)]. The interfacial of co-polymer formed during the reactive compatibilization with the MDI contributed to the change in the shape of the dispersed phase from smooth spheres to a more fibrillar morphology. Dynamic mechanical analysis measurements also indicate enhancement of compatibility of the PLA/PBAT-MDI blends. Tan $\delta$ peak increases from about $-25{ }^{\circ} \mathrm{C}$ for pure PBAT to above $-21.3{ }^{\circ} \mathrm{C}$, while the $T_{\mathrm{g}}$ of PLA was decreased from $64.3{ }^{\circ} \mathrm{C}$ to $63.0^{\circ} \mathrm{C}$ after adding MDI. There might be two reasons for the elevation of the $T_{\mathrm{g}}$ value. One is that a number of hydroxyl and carboxyl end groups of the PLA that participate in the chain elongation reaction at the start of reaction, chain extension by adding MDI increased the molecular weight and reduced the number of end groups. In addition, the introduction of a rigid aromatic structure into the polymer chain hinders the chain movement. As discussed previously in Scheme 1, chain extension reactions led to the formation of PLA-MDI-PBAT polymers. The varied morphology, coupled with chemical interaction between the functional groups of the two polyesters, may affect mobility of the phases, and result in a shift of glass transition temperature with respect to the expected values. ${ }^{46}$

A concomitant drop in storage modules $\left(E^{\prime}\right)$ curves occurs at similar temperatures in Fig. 6(b). The $E^{\prime}$ shows two apparent peaks for the blends, indicating the presence of two different continuous phases in the blends at a microscopic level. Evidently, this peak is an indicative of the glass transition
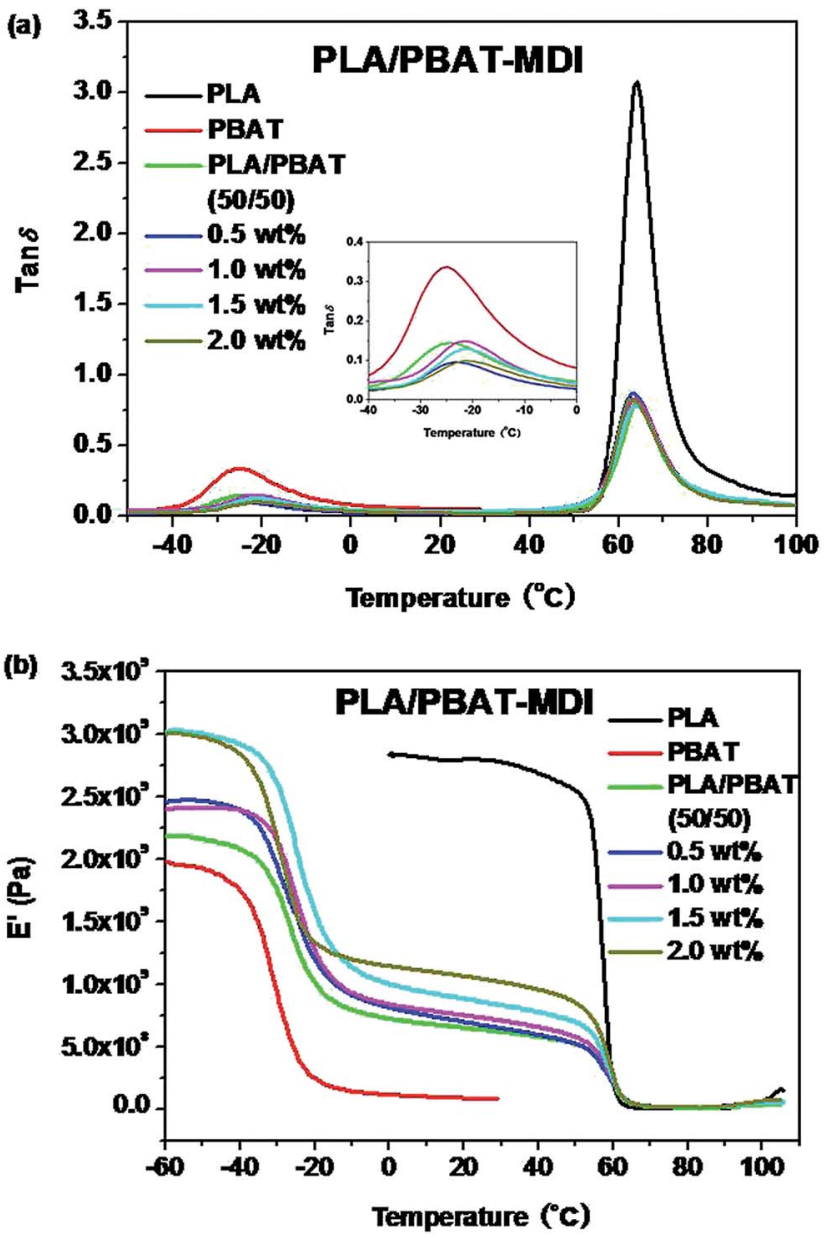

Fig. 6 DMA traces of the neat polymers and the polymer blends: (a) temperature dependence of $\tan \delta$; (b) temperature dependence of the storage modulus $\left(E^{\prime}\right)$.

temperature, containing both PLA and PBAT in proportions that critically depend on overall blend compositions and the conditions during the preparation of the blends. The pure PLA displays a high $E^{\prime}$ at about $3.0 \mathrm{GPa}$, which remains in the same order up to $60^{\circ} \mathrm{C}$, while neat PBAT shows a smoother drop in $E^{\prime}$ at about $-30{ }^{\circ} \mathrm{C}$. For the PLA/PBAT-MDI blends, $E^{\prime}$ drops at about -20 to $60{ }^{\circ} \mathrm{C}$, when the fraction of MDI becomes higher, a higher drop appears at temperatures that is due to form a microstructure of PLA-crosslink-PBAT copolymers.

\subsection{Thermal analysis}

The DSC thermograms of the blends are presented in Fig. 7, and values of the cold-crystallization temperature $\left(T_{\mathrm{cc}}\right)$, melting temperature $\left(T_{\mathrm{m}}\right)$, melting enthalpy $\left(\Delta H_{f}\right)$, cold crystallization enthalpy $\left(\Delta H_{\mathrm{cc}}\right)$, glass transition temperature $\left(T_{\mathrm{g}}\right)$ and the degree of crystallinity $\left(X_{\mathrm{c}}\right)$ of the unoriented and oriented blends related to the first heating run are summarized in Tables 1 and 2 .

On the one hand, pure PLA shows a $T_{\mathrm{g}}$ of $63.7^{\circ} \mathrm{C}$ and a strong endothermic peak at $170.9^{\circ} \mathrm{C}$. On the other hand, pure PBAT is a soft elastomeric material with a $T_{\mathrm{g}}$ of only $-31.0{ }^{\circ} \mathrm{C}$ and 

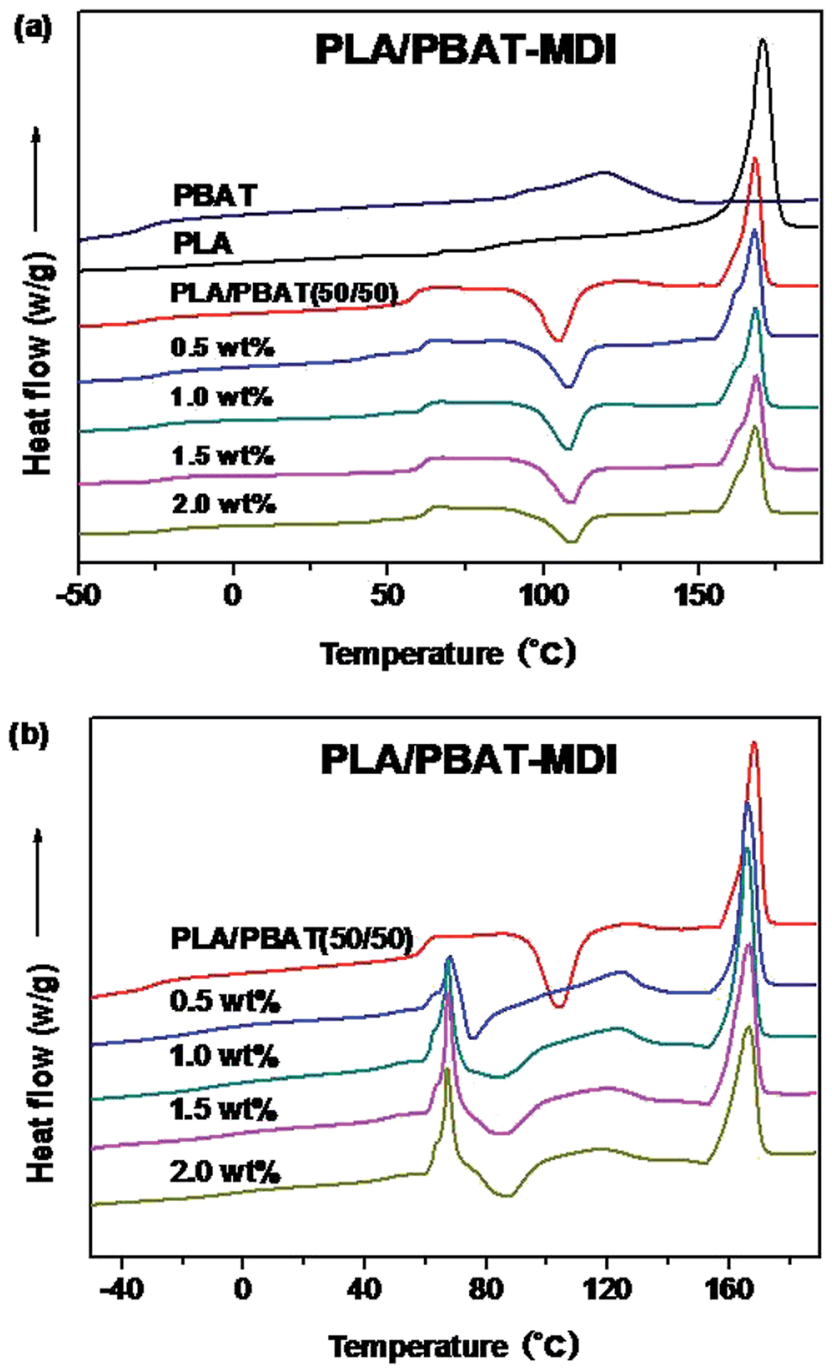

Fig. 7 DSC thermograms of unoriented (a) and oriented (b) PLA/ PBAT-MDI blends in the first heating run.

followed by a small single endothermic peak of $124.5{ }^{\circ} \mathrm{C}$. Compatibility in polymer blends can be judged by observing the shift in the $T_{\mathrm{g}}$ of the phases in comparison to their original values. ${ }^{35}$ Since the PLA/PBAT is an immiscible system, each component should present its own bulk behaviors in the blend, including thermal properties. ${ }^{47}$ As the Fig. 7(a) shown, for the PLA/PBAT $(50 / 50)$ blend, $T_{\mathrm{g}}$ of PLA at $58.2{ }^{\circ} \mathrm{C}$ had a slight reduction due to incorporate the PBAT, as reported in the literature previously. ${ }^{48}$ For the PLA/PBAT-MDI (2.0\%) blend, the $T_{g}$ values of PBAT are significantly higher than that of the pure PBAT, which can be increased about $6.0{ }^{\circ} \mathrm{C}$. The value of $T_{\mathrm{g}}$ between those of PLA and PBAT and increased with the increase of MDI. The results indicated that the PLA were well compatible with PBAT segments in the amorphous phase and compatibility improved in the formed blends. This result is accordant with DMA analysis. It can be seen from Fig. 7(a) that the PLA/PBATMDI blends show a small platform on the melting peak. This had been widely investigated and believed to be attributed to the melting and recrystallization mechanism..$^{43,49,50}$ As the chain extension interfered in the crystallization process, many imperfect crystallites could be formed, and a large number of terminal groups and branched points generated imperfect crystallization. ${ }^{51}$ In comparison with those of the neat PLA, the melting peak shape and amount of the blends exhibit almost no change. In Fig. 7(a), for the PLA/PBAT-MDI blends, there is an overlap between the PBAT melting region and the PLA cold crystallization region in the first heating run. The $T_{\mathrm{cc}}$ moved to a higher temperature than that of the PLA/PBAT blend, it increased from $105.4{ }^{\circ} \mathrm{C}$ to $108.0{ }^{\circ} \mathrm{C}$ in the PLA/PBAT-MDI blend, demonstrating that chain extension reduced the crystallization of PLA.

Fig. 7(b) shows the thermal parameters of oriented blends in the first heating run, it can be seen that a sharp endotherm of blends is present for the oriented PLA/PBAT-MDI blends. It is worth noticing that this endotherm turns out to be as much important as the melting endotherm at strains. The peak of endotherm is occurred, the main reason is that a hint of cold crystallization promoted by the strain-induced orientation of the amorphous chains of PLA. ${ }^{52}$ Fig. $7(\mathrm{~b})$ also shows that cold crystallization of PLA and melting peak of PBAT are observed concurrently for oriented polymers, the values are different from the unoriented polymers. The cold crystallization exotherm appears in the range $70-90{ }^{\circ} \mathrm{C}$, the evolution of the crystallization enthalpy listed in Table 2 . Oriented PLA/PBATMDI blend component exhibits a melting temperature of PBAT decreased from 124.7 to $117.5^{\circ} \mathrm{C}$. The melting peak of PLA in PLA/PBAT-MDI $\left(166.7^{\circ} \mathrm{C}\right)$ is also observed much smaller than that of PLA/PBAT blend $\left(168.4{ }^{\circ} \mathrm{C}\right)$, and the crystallinity of the

Table 1 Thermal parameters of unoriented PLA/PBAT-MDI blends in the first heating run

\begin{tabular}{|c|c|c|c|c|c|c|c|c|c|}
\hline Samples & $T_{\text {gPBAT }}\left({ }^{\circ} \mathrm{C}\right)$ & $T_{\text {gPLA }}\left({ }^{\circ} \mathrm{C}\right)$ & $T_{\text {mPLA }}\left({ }^{\circ} \mathrm{C}\right)$ & $\Delta H_{f}\left(\mathrm{~J} \mathrm{~g}^{-1}\right)$ & $X_{\mathrm{c}}(\%)$ & $T_{\text {mPBAT }}\left({ }^{\circ} \mathrm{C}\right)$ & $T_{\text {gPLA }}\left({ }^{\circ} \mathrm{C}\right)$ & $T_{\text {gPBAT }}\left({ }^{\circ} \mathrm{C}\right)$ & $\mathrm{T}_{\mathrm{cc}}\left({ }^{\circ} \mathrm{C}\right)$ \\
\hline PLA & - & 63.7 & 170.9 & 37.6 & 40.4 & - & - & - & - \\
\hline PBAT & -25.0 & - & - & 11.5 & 10.1 & 124.5 & - & -31.0 & - \\
\hline PLA/PBAT (50/50) & -24.5 & 64.3 & 168.3 & 22.3 & 47.9 & - & 58.2 & -28.8 & 104.6 \\
\hline $1.5 \mathrm{wt} \%$ & -21.1 & 63.6 & 168.2 & 19.1 & 41.0 & - & 62.4 & -25.0 & 108.7 \\
\hline $2.0 \mathrm{wt} \%$ & -20.5 & 63.6 & 167.8 & 17.5 & 37.6 & - & 62.2 & -24.1 & 108.8 \\
\hline
\end{tabular}


Table 2 Thermal parameters of oriented PLA/PBAT-MDI blends in the first heating run

\begin{tabular}{|c|c|c|c|c|c|c|c|c|c|}
\hline Sample & \multicolumn{9}{|l|}{ DSC } \\
\hline PLA/PBAT (50/50) & 168.4 & 59.3 & 104.6 & 21.8 & 46.8 & 126.4 & -29.4 & 7.9 & 13.8 \\
\hline $0.5 \mathrm{wt} \%$ & 166.2 & 68.0 & 74.8 & 21.8 & 46.8 & 124.7 & -15.7 & 6.2 & 10.8 \\
\hline $1.0 \mathrm{wt} \%$ & 166.1 & 67.2 & 84.1 & 22.7 & 48.8 & 123.4 & -10.2 & 5.0 & 8.7 \\
\hline
\end{tabular}

PLA decreases to $43.2 \%$ in Table 1 . The decrease in melting temperature indicates that the lamellar crystallization structure is destroyed gradually during deformation.

\subsection{In situ WAXD/SAXS measurements}

The difference in deformational response is accompanied by a difference in the development of crystalline structure. Since the properties of semicrystalline polymers such as PLA and PBAT depend on their crystalline structure, in this study, the effect of stretching on orientation of the crystallites was investigated using wide-angle X-ray diffraction (WAXD).

(a)

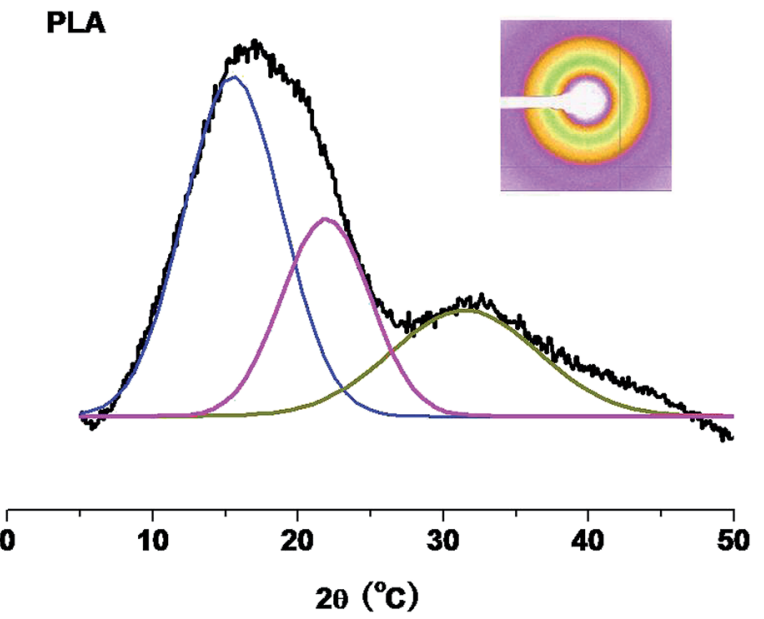

(b)

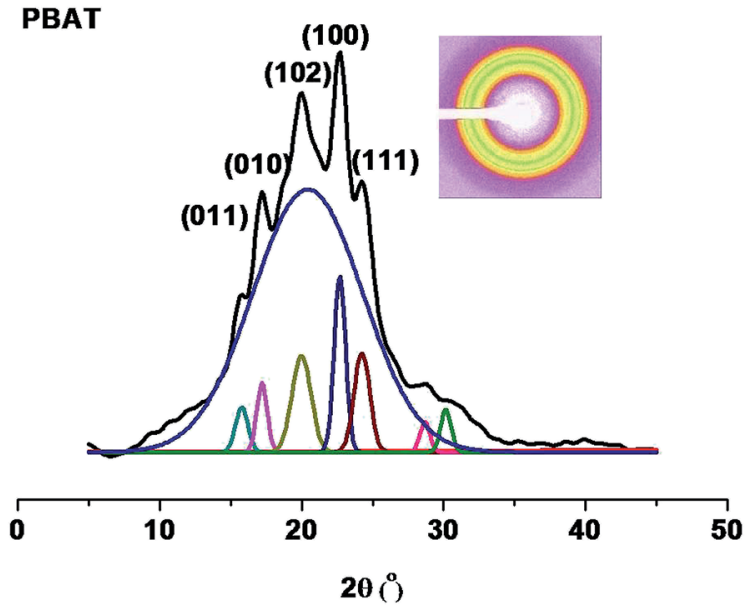

Fig. 8 Resolution of the WAXD curves: (a) pure PLA, (b) pure PBAT.
It is well known that the mechanical properties and phase behavior of crystalline biodegradable polymers depend on their crystalline structure, thus the characterization of their solidstate morphology is very important. ${ }^{53,54}$ As the Fig. 8 shown, PLA exhibits an amorphous (Fig. 8(a)) and PBAT exhibits a small crystalline (Fig. 8(b)), whereas no diffraction peak of PLA is observed diffraction for all PLA/PBAT-MDI blends compositions. Hence just the PBAT fraction is considered as being the crystalline phase of the blends. The X-ray diffraction study
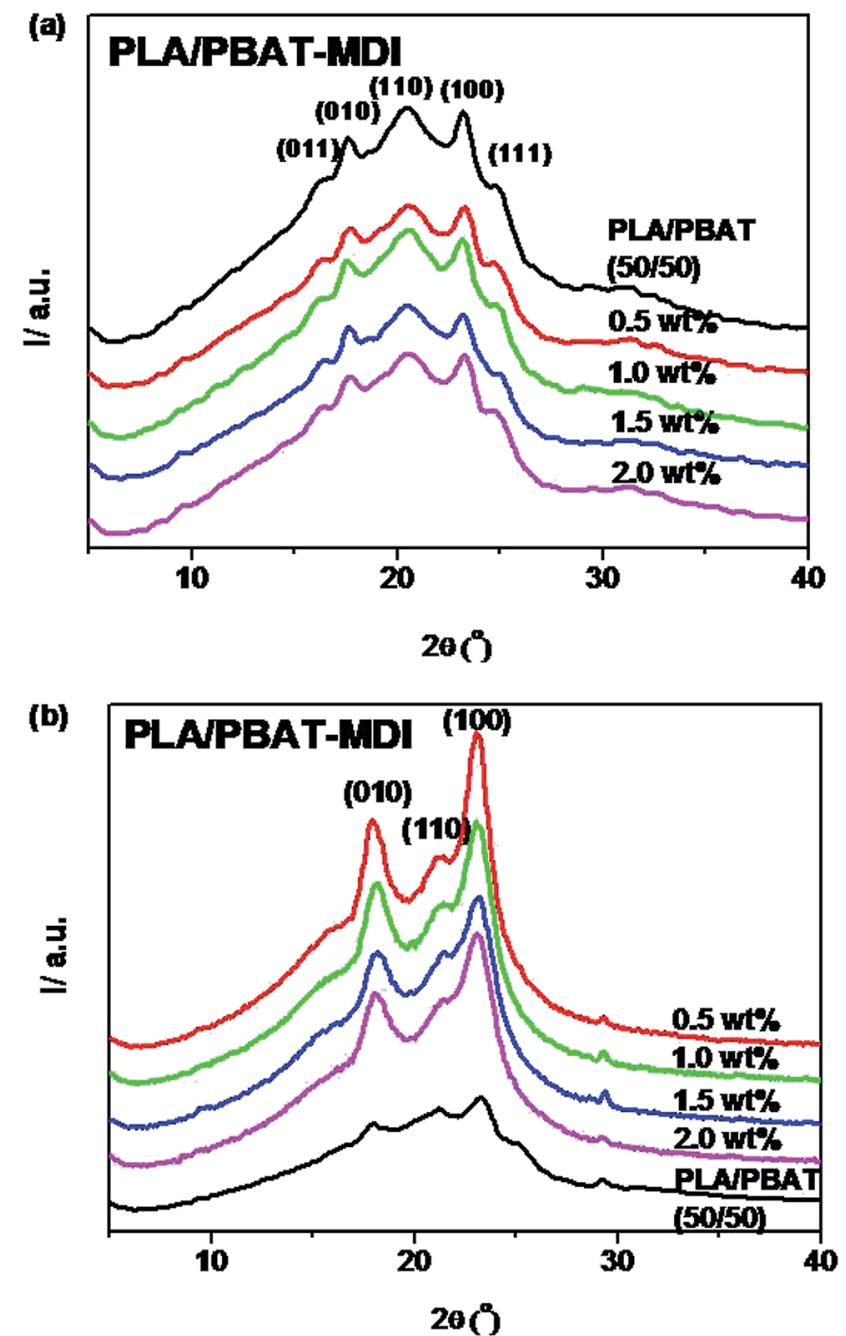

Fig. 9 The wide-angle $X$-ray diffraction pattern of PLA/PBAT-MDI blends: (a) unoriented, (b) oriented. 
revealed that PBAT is a crystalline material yielding the same diffraction maxima as PBT. ${ }^{55}$ Similar diffraction patterns suggested that the unit cell dimensions of PBAT should be similar to that of PBT. Thus it is plausible to speculate that the crystal structure of PBAT was formed by BT unit. ${ }^{56}$

For acquiring the crystallinity and orientation of deformed blends, the one-dimensional diffraction intensity along $2 \theta$ has been obtained by integration over the azimuthal range $\left(0-360^{\circ}\right)$ from the two-dimensional diffraction, as shown in Fig. 9. The variation of ratio PLA/PBAT-MDI in this experiment is shown in Fig. 9(a). For the sample with $50 \mathrm{wt} \%$ of PBAT, the reflections of PBAT crystals at $2 \theta=16.2,17.3,20.4,23.2$ and $24.8^{\circ}$ are still observed, indicating that the PBAT crystalline phase should be well separated in the blend. It is obvious that the crystallite dimensions of the samples become smaller with increasing MDI content. The calculated values of ACS are listed in Table 3. The smaller crystallite size seems to suggest that fewer nuclei are present in the blends during crystallization. This indicated

Table 3 Crystallite dimension of the PLA/PBAT-MDI blends

\begin{tabular}{llllll}
\hline & \multicolumn{1}{l}{ ACS $(\AA)$} & & & \\
\cline { 2 - 5 } Sample & $(011)$ & $(010)$ & $(110)$ & $(100)$ & $(111)$ \\
\hline
\end{tabular}

(a) Unoriented

$1.0 \mathrm{wt} \%$ PLA/PBAT (50/50)

$0.5 \mathrm{wt} \%$

91.4

89.0

87.3

87.1

$1.5 \mathrm{wt} \%$

$2.0 \mathrm{wt} \%$

$\begin{array}{ll}88.5 & 57.6 \\ 85.5 & 47.1 \\ 83.8 & 44.3 \\ 83.2 & 37.9 \\ 66.5 & 36.0\end{array}$

57.6

47.1

37.9

36.0
98.7

88.3

75.2

66.7

55.5 that the presence of MDI had strong influence on the crystallization of blends. From the Fig. 9(b), the stretched blends in uniaxially exhibits a very high orientation in crystalline domains. The diffraction peaks of 010 (17.3) and 110 (20.4) were shifted to a higher $2 \theta$ values $\left(17.8^{\circ}\right.$ and $\left.21.2^{\circ}\right)$ after oriented. One sharp diffraction peaks at around 23.8 , which are characteristic of the defective $\alpha$-form crystal in PLA. The peak at $2 \theta=$ $29.9^{\circ}$ corresponds to $\beta$-forms crystals of PBAT. Song et al. also reported that PBAT crystallized in two crystalline modifications, $\alpha$ and $\beta$ forms. ${ }^{57}$ These changes in the diffraction pattern explain that the crystalline transform from the $\alpha$ form to the $\beta$ form after stretching. Subsequently, with stretching, the $\beta$ form crystals that have small sizes may arise through the extended-chain crystallization and/or the $\alpha, \beta$ form crystal transition of the imperfect an ordering.

Fig. 10 shows the diffraction pattern scanned along the equator of each profiles in Fig. 9. The initial pattern of the unoriented sample in Fig. 10[(a)-(e)] shows a diffuse isotropic halo. It can be seen that the diffuse halo of the WAXD pattern is isotropic, indicating that the undrawn PLA/PBAT-MDI blend is nearly semicrystalline and there is no oriented structure in it. As drawing proceeds there is a gradual intensification of the halo on the equator leading to diffuse equatorial spots in Fig. 10[( $\left.\left.\mathrm{a}^{\prime}\right)-\left(\mathrm{e}^{\prime}\right)\right]$, characteristic of a highly oriented crystalline structure. Note that the diffraction halo of the amorphous phase gradually developed into a pair of broad diffraction arcs on the meridional position at

(b) Oriented PLA/PBAT (50/50) $0.5 \mathrm{wt} \%$ 65.6

$\begin{array}{rrrr}65.6 & 51.3 & 59.0 & 66.4 \\ & 75.5 & 47.9 & 66.2 \\ & 68.4 & 52.6 & 57.4 \\ & 66.4 & 53.5 & 54.9 \\ & 65.7 & 55.1 & 52.8\end{array}$

$1.0 \mathrm{wt} \%$

$1.5 \mathrm{wt} \%$

$2.0 \mathrm{wt} \%$ a MDI of around $0.5 \mathrm{wt} \%$. In general, uniaxial PLA/PBAT-MDI blends revealed distinct crystalline arcs in WAXS flat blends photographs. The equatorial diffraction profiles were obtained by scanning respective patterns along the equatorial direction, perpendicular to the drawing direction. When the MDI was up to $2.0 \mathrm{wt} \%$, the diffraction of the spots was more intense and a pair

\section{8}

73.0

of short and narrow arcs appeared outside the spots, indicating that the degree of crystallinity increased. As the MDI content increased, the $\beta$ peaks arose on the meridian, developing anisotropy. Thus, in order to understand the deformation
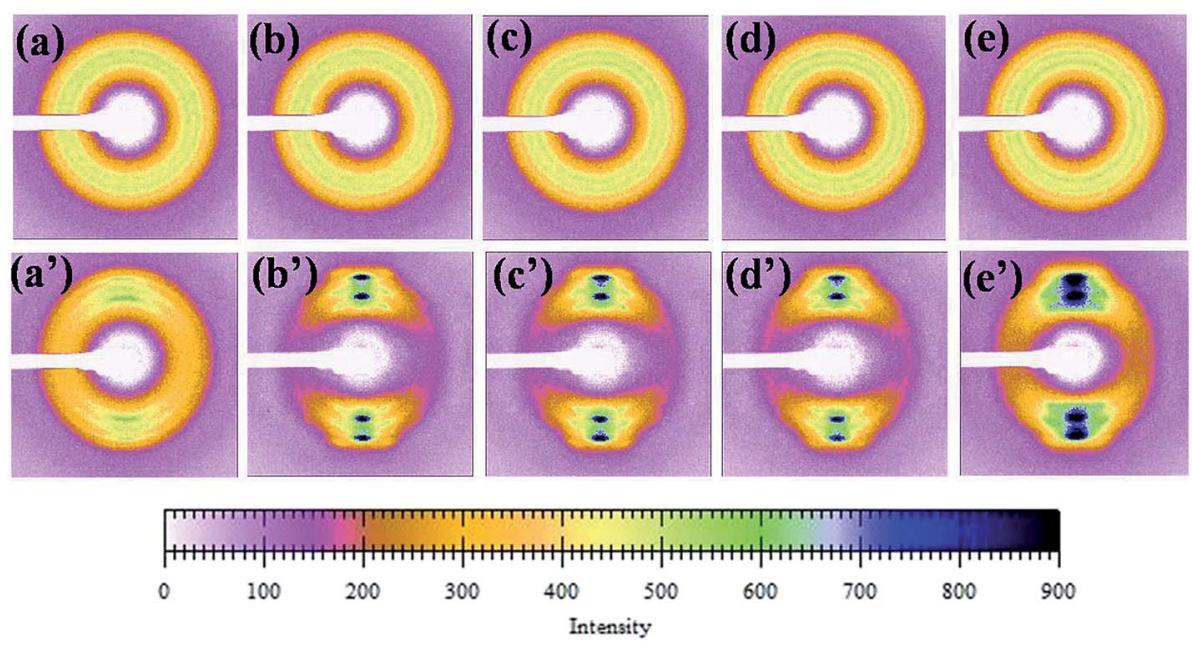

Fig. 10 A series of WAXD diffraction patterns were taken sequentially according to the scheme of Fig. 8 (unoriented PLA/PBAT-MDI samples: (a) PLA/PBAT (50/50), (b) $0.5 \mathrm{wt} \%$, (c) $1.0 \mathrm{wt} \%$, (d) $1.5 \mathrm{wt} \%$ and (e) $2.0 \mathrm{wt} \% \mathrm{MDI}$; oriented PLA/PBAT-MDI samples: (a') PLA/PBAT (50/50) (b') 0.5 wt\%, (c') $1.0 \mathrm{wt} \%$, (d') $1.5 \mathrm{wt} \%$ and (e') $2.0 \mathrm{wt} \% \mathrm{MDI})$. 

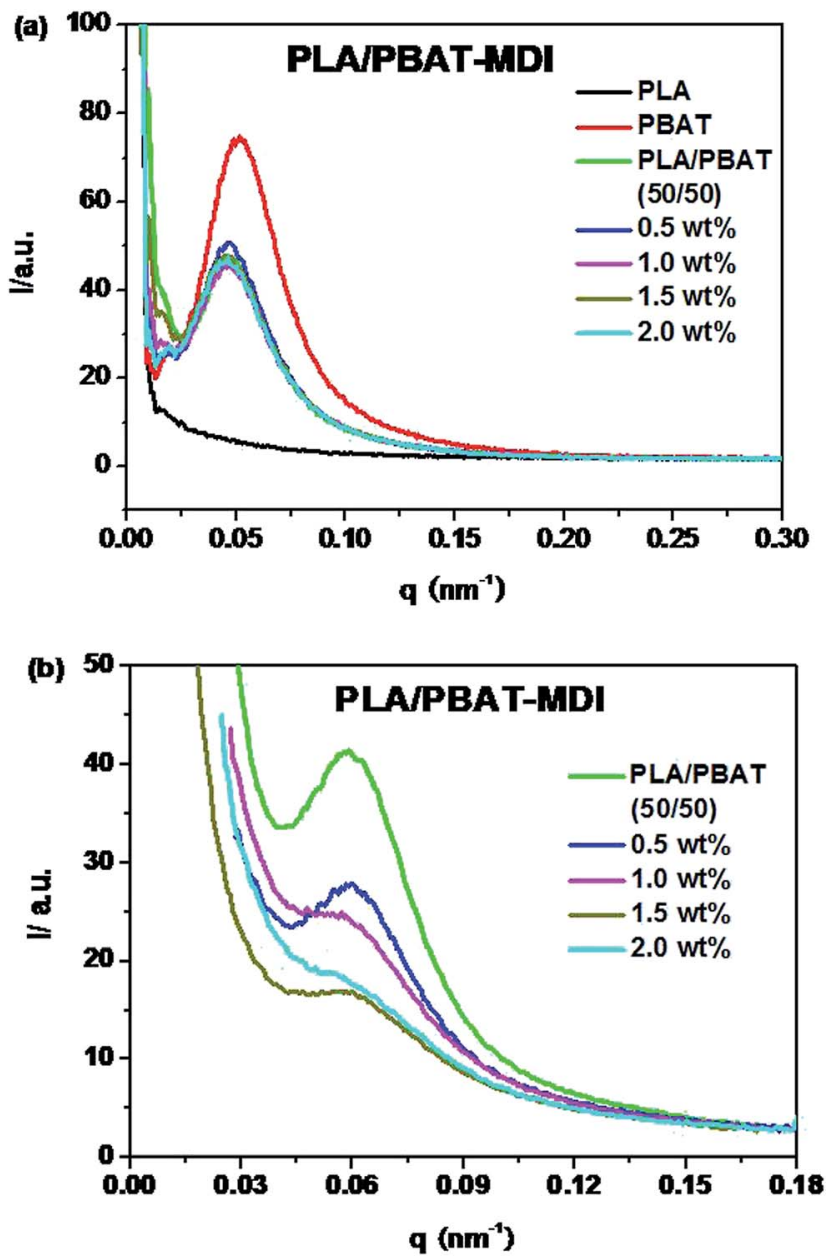

Fig. 11 One-dimensional scattering intensity distribution of PLA/ PBAT-MDI blends: (a) unoriented (b) oriented.

behavior of this or other crystalline polymer systems, which have more than one crystalline phase, it is important to know the stress-strain relationship in the region of crystalline transition.
Table 4 SAXS values of oriented PLA/PBAT-MDI blends

\begin{tabular}{llrlrr}
\hline Sample & $q_{\max }\left(\mathrm{nm}^{-1}\right)$ & $X_{\mathrm{c}}(\%)$ & $d_{\mathrm{ac}}(\mathrm{nm})$ & $d_{\mathrm{c}}(\mathrm{nm})$ & $d_{\mathrm{a}}(\mathrm{nm})$ \\
\hline PLA/PBAT (50/50) & 0.060 & 13.8 & 104.6 & 14.4 & 100.2 \\
$0.5 \mathrm{wt} \%$ & 0.059 & 10.8 & 106.4 & 11.5 & 94.9 \\
$1.0 \mathrm{wt} \%$ & 0.057 & 8.7 & 110.1 & 9.6 & 100.5 \\
$1.5 \mathrm{wt} \%$ & 0.057 & 8.2 & 110.1 & 9.0 & 101.1 \\
$2.0 \mathrm{wt} \%$ & 0.055 & 6.8 & 114.2 & 7.7 & 106.5 \\
\hline
\end{tabular}

In order to interpret the effect of crystallization on the toughness of the blend, small-angle X-ray scattering (SAXS) was used to investigate the lamellar structures. Because of survival of these crystalline lamellae after deformation, the scattering intensity distribution of the PLA/PBAT-MDI blend obtained by equatorial scan along the scattering streak was decomposed into two contributions based on Lorentzian functions, as given in Fig. 11. In an effort to elucidate the evolution of the lamellar after deformation, scattering patterns of PLA/PBAT-MDI blends measured before and after stretching direction are plotted in Fig. 12. The obtained $q_{\mathrm{max}}$, long period $\left(d_{\mathrm{ac}}\right)$, lamellar thickness $\left(d_{\mathrm{c}}\right)$ and amorphous thickness $\left(d_{\mathrm{a}}\right)$ values are summarized in Table 4 . The $q_{\max }$ represents the position of the intensity maximum in a SAXS pattern, $X_{\mathrm{c}, 2}$ represents the crystallinity of the PBAT samples, which was derived from DSC measurement.

Because of the electron density difference between crystalline and amorphous phase, the SAXS intensity of PLA is very weak. As the Fig. 11(a) shown, the intensity at $I_{\max }$ and $q_{\max }$ decreases with the various MDI present in unstretched PLA/ PBAT-MDI blends samples compared with pure PBAT. The decrease in SAXS intensity indicates that the original lamellar structure is destroyed gradually during deformation. Compared to the foregoing discussion one might also consider the possibility of kinking deformation of lamellae as proposed by Bartczak and Lezak. ${ }^{58}$ Fig. 11(b) shows oriented samples scattering character. It is obvious that all of the values of $d_{\mathrm{ac}}$ and $d_{\mathrm{a}}$ increase and the $d_{\mathrm{c}}$ values decrease with increasing MDI.

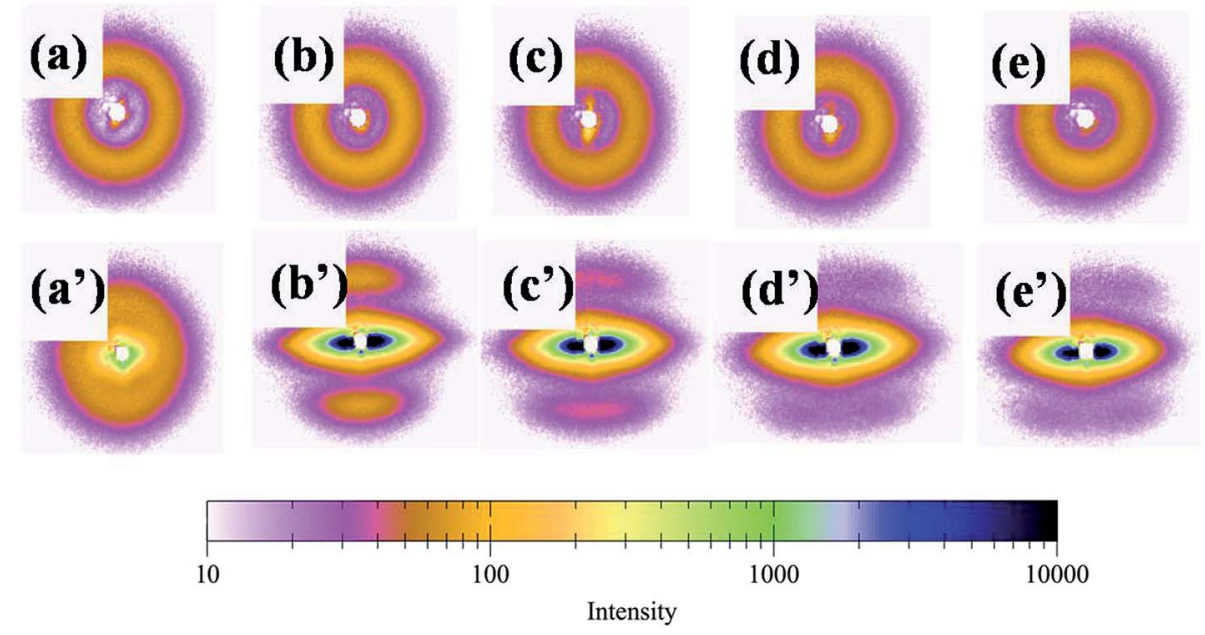

Fig. 12 Selected small-angle X-ray scattering patterns of PLA/PBAT-MDI blends measured before and after tensile deformation (unoriented PLA/ PBAT-MDI samples: (a) PLA/PBAT (50/50), (b) $0.5 \mathrm{wt} \%$, (c) $1.0 \mathrm{wt} \%$, (d) $1.5 \mathrm{wt} \%$ and (e) $2.0 \mathrm{wt} \%$ MDI; oriented PLA/PBAT-MDI samples: (a') PLA/ PBAT (50/50) (b') $0.5 \mathrm{wt} \%$, (c') $1.0 \mathrm{wt} \%$, (d') $1.5 \mathrm{wt} \%$ and $\left.\left(\mathrm{e}^{\prime}\right) 2.0 \mathrm{wt} \% \mathrm{MDI}\right)$. 
A

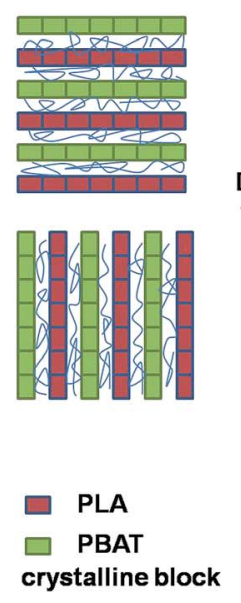

B
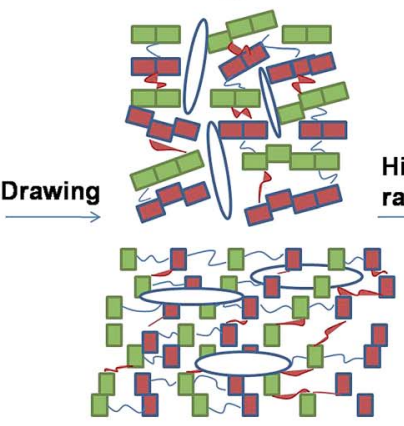

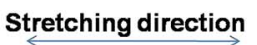

chain between blocks

amorphous chain
C

Fig. 13 Schematic model of the evolution of cavitation in blends during stretching.

However, the increase in $d_{\mathrm{a}}$ is large. For example, the increase in $d_{\mathrm{a}}$ is around $6.0 \mathrm{~nm}$ after blending $2 \mathrm{wt} \%$ MDI as compared to that of neat PBAT. The data indicate that the increase of long spacing is mostly due to the increase of amorphous layer thickness. Such significant increase in $d_{\mathrm{a}}$ suggested that chain extension may destroy the crystalline of blends and reside in the interlamellar region of PLA.

In semi-crystalline polymers, a two-phase morphology consisting of lamella shaped crystals is widely researched and quantitative details of such morphology can be estimated by SAXS, with often remarkable accuracy. ${ }^{59-61}$ The SAXS patterns of unoriented and oriented PLA/PBAT-MDI blends exhibit faint polar scattering intensifying and the original isotropic scattering distributed to highly anisotropic streak-like scattering patterns can be observed in Fig. 12. Initially, the original scattering intensity in the meridian direction becomes weaker, which is caused by a destruction of crystalline lamellae with the drawing direction.

Cavitation behavior in blends upon stretching below glass transition temperature was investigated by SAXS technique. The crystallinity lamellae decreased with the increase of amorphous phase, resulting in high stretching stress at the same strain (Fig. 2) and consequently producing more voids and cavities in the amorphous phase between the crystals during stretching. Strong stress-whitening was observed indicating an extensive occurrence of cavitation in the material during tensile deformation below $T_{\mathrm{g}}$. A schematic representation of the evolution of cavitation in PLA/PBAT-MDI blends during uniaxial deformation is shown in Fig. 13. The lamellar thickness is small, interlamellar slips take place resulting in an increase in orientational order parameter at the early stage of deformation. The block boundaries within crystalline lamellae with perpendicular to the tensile direction opened in width and formed the platelike cavities passing through amorphous phase connecting several lamellae. After yield point, the plate-like cavities perpendicular to the tensile direction became bigger. Here the polymer chains were perpendicular to the stretching direction. During strain-hardening stage, the part of the polymer chains oriented to the stretching direction resulting in a reorientation of the cavities with their normal perpendicular to the stretching direction. ${ }^{62}$

Information about changes in the lamellar structure during tensile deformation can be extracted directly from the in WAXD patterns. The crystalline dimension become smaller if the crystallization is reduced or noncrystalline parts are increased due to chain extension. ${ }^{63}$ With the addition of MDI, the SAXS patterns transformed from a scattering diagram, parallel to the flow direction at small deformations, and eventually to a highly anisotropic scattering intensity distribution with scattering peaks aligned in the strength direction. ${ }^{64}$ The smaller crystallites of blends are likely to be formed during the course of chain extension after crystallization, which can be verified by the fact that the size differences of blends from the Table $4 .{ }^{65}$

\section{Conclusions}

In this work, the impact strength of biodegradable PLA and PBAT blends was significantly enhanced successfully by using MDI as chain extender through reactive melt processing. The effect of mechanical properties and crystallization on the microstructure of a toughened PLA/PBAT blends was studied. The effect of chain extension on the toughness of the blend was associated with the mechanical properties, morphology, thermal and crystal behavior which mainly affected the ability of the matrix to deform. Upon increasing the content of the MDI, the blends showed increased yield tensile strength, modulus, and elongation at break. The improvement in resistance to impact was attributed to yielding deformation between PLA and PBAT phases. The miscibility of PLA/PBAT blends was studied by DMA, the results showed a partial miscibility between PLA and PBAT phase. DSC analysis suggested that PLA and PBAT segments were well compatible in amorphous phase, and the amorphous phase was predominantly caused by chain extension of MDI, which was also confirmed by WAXD and SAXS study. The effect of chain extension on the toughness of the blend was associated with the degree of crystallinity, 
morphology, and lamellar thickness. It is evident that the lamellar crystallization structure to fibrillar transition of oriented samples just is strongly dependent on the content of MDI, due to an enhanced mobility of the amorphous phase, therefore, a reduced crystallite dimension of the entangled amorphous network. Consequently, the toughened PLA/PBATMDI blend can be useful for the choice of appropriate materials for specific applications.

\section{Conflicts of interest}

There are no conflicts to declare.

\section{Acknowledgements}

This work was supported by the fund of Science \& Technology Bureau of Jilin Province of China (No. 20160307001GX), and National Key Research and Development Program of China (No. 2016YFC0501402-5), Science \& Technology Bureau of Changchun City of China (No. 16SS03), Chinese Science Academy (Changchun Branch) (No. 2017SYHZ0016), and Chinese Science Academy (Changchun Branch) (No. 2017SYHZ0018).

\section{References}

1 M. Gao, Z. J. Ren, S. K. Yan, J. R. Sun and X. S. Chen, J. Phys. Chem. B, 2012, 116, 9832-9837.

2 X. F. Ma, J. G. Yu and N. Wang, J. Polym. Sci., Part B: Polym. Phys., 2006, 44, 94-101.

3 L. D. Feng, X. C. Bian, G. Li, Z. M. Chen and X. S. Chen, Polym. Degrad. Stab., 2016, 125, 148-155.

4 G. Flodberg, I. Helland, L. Thomsson and S. Bodil Fredriksen, Eur. Polym. J., 2015, 63, 217-226.

5 Q. R. Sun, T. Mekonnen, M. Misra and A. K. Mohanty, J. Polym. Environ., 2015, 24, 23-36.

6 L. Y. Zhou, G. Y. Zhao and W. Jiang, Ind. Eng. Chem. Res., 2016, 55, 5565-5573.

7 M. Kumar, S. Mohanty, S. K. Nayak and M. R. Parvaiz, Bioresour. Technol., 2010, 101, 8406-8415.

8 W. Phetwarotai, V. Tanrattanakul and N. Phusunti, Plast., Rubber Compos., 2016, 45, 333-345.

9 S. Ravati, C. Beaulieu, A. M. Zolali and B. D. Favis, AIChE J., 2014, 60, 3005-3012.

10 N. Shi and Q. Dou, J. Therm. Anal. Calorim., 2014, 119, 635642.

11 D. D. Ju, L. J. Han, F. Li, S. Chen and L. S. Dong, Polym. Compos., 2013, 34, 1745-1752.

12 C. Zhang, T. Zhai, L. S. Turng and Y. Dan, Ind. Eng. Chem. Res., 2015, 54, 9505-9511.

13 F. Walha, K. Lamnawar, A. Maazouz and M. Jaziri, Polymers, 2016, 8, DOI: 10.3390/polym8030061.

14 S. Lee and J. W. Lee, Korea Aust. Rheol. J., 2005, 17, 71-77.

15 G. X. Chen, H. S. Kim, E. S. Kim and J. S. Yoon, Polymer, 2005, 46, 11829-11836.

16 A. Bhatia, R. K. Gupta, S. N. Bhattacharya and H. J. Choi, Korea Aust. Rheol. J., 2007, 19, 125-131.
17 L. J. Han, C. Y. Han and L. S. Dong, Polym. Compos., 2013, 34, 122-130.

18 L. J. Han, C. Y. Han and L. S. Dong, Polym. Int., 2013, 62, 295303.

19 Y. J. Chen, L. J. Han and Z. L. Li, RSC Adv., 2017, 7, 712-719.

20 Z. Y. Jiang, Y. T. Wang, L. L. Fu, B. Whiteside, J. Wyborn, K. Norris, Z. H. Wu, P. Coates and Y. F. Men, Macromolecules, 2013, 46, 6981-6990.

21 M. Psarskia, M. Pracellab and A. Galeski, Polymer, 2000, 41, 4923-4932.

22 U. Witt, R. J. Muller and W. D. Deckwer, Macromol. Chem. Phys., 1996, 197, 1525-1535.

23 S. Girdthep, N. Komrapit, R. Molloy, S. Lumyong, W. Punyodom and P. Worajittiphon, Compos. Sci. Technol., 2015, 119, 115-123.

24 G. Schmack, D. Jehnichen, R. Vogel, B. Tandler, R. Beyreuther, S. Jacobsen and H. G. Fritz, J. Biotechnol., 2001, 86, 151-160.

25 M. A. Huneault and H. Li, Polymer, 2007, 48, 270-280.

26 H. Y. Zhou, H. D. Huang and X. Ji, ACS Appl. Mater. Interfaces, 2016, 8, 8096-8109.

27 E. J. Dil, P. J. Carreau and B. D. Favis, Polymer, 2015, 68, 202212.

28 L. C. Arruda, M. Magaton, R. E. S. Bretas and M. M. Ueki, Polym. Test., 2015, 43, 27-37.

29 R. Al-Itry, K. Lamnawar and A. Maazouz, Polym. Degrad. Stab., 2012, 97, 1898-1914.

30 R. Al-Itry, K. Lamnawar and A. Maazouz, Eur. Polym. J., 2014, 58, 90-102.

31 R. Al-Itry, K. Lamnawara and A. Maazouz, Eur. Polym. J., 2015, 68, 288-301.

32 R. Al-Itry, K. Lamnawar and A. Maazouz, Rheol. Acta, 2014, 53, 501-517.

33 K. B. H. Badri, W. C. Sien, M. S. B. R. Shahrom, L. C. Hao, N. Y. Baderuliksan and N. R. A. Norzali, Solid State Sci. Technol., 2010, 18, 1-8.

34 B. H. Li and M. C. Yang, Polym. Adv. Technol., 2006, 17, 439443.

35 F. Zhao, H. X. Huang and S. D. Zhang, J. Appl. Polym. Sci., 2015, 132, 42511.

36 H. Wang, X. Sun and P. J. Seib, J. Appl. Polym. Sci., 2002, 84, 1257-1262.

37 W. Zhong, J. J. Ge, Z. Y. Gu, W. J. Li, Z. Y. Gu, W. J. Li, X. Chen, Y. Zang and Y. L. Yang, J. Appl. Polym. Sci., 1999, 74, 2546-2551.

38 Z. Z. Su, Q. Y. Li, Y. J. Liu, G. H. Hu and C. F. Wu, Eur. Polym. J., 2009, 45, 2428-2433.

39 M. Kakudo and N. Kasai, X-Ray Diffraction by Polymer, Kodansha Press, Tokyo, 1972.

40 H. Tsuji, K. Ikarashi and N. Fukuda, Polym. Degrad. Stab., 2004, 84, 515-523.

41 V. Ojijo and S. S. Ray, Polymer, 2015, 80, 1-17.

42 V. Ojijo, S. S. Ray and R. Sadiku, ACS Appl. Mater. Interfaces, 2012, 4, 6690-6701.

43 V. Ojijo, S. S. Ray and R. Sadiku, ACS Appl. Mater. Interfaces, 2013, 5, 4266-4276. 
44 X. M. Wang, Y. G. Zhuang and L. S. Dong, J. Appl. Polym. Sci., 2013, 127, 471-477.

45 A. K. Kalkar, H. W. Siesler, F. Pfeifer and S. A. Wadekar, Polymer, 2003, 44, 7251-7264.

46 V. Thirtha, R. Lehman and T. Nosker, Polymer, 2006, 47, 5392-5401.

47 D. F. Wu, L. J. Yuan, E. Laredo, M. Zhang and W. D. Zhou, Ind. Eng. Chem. Res., 2012, 51, 2290-2298.

48 L. Jiang, M. P. Wolcott and J. W. Zhang, Biomacromolecules, 2006, 7, 199-207.

49 M. Akrami, I. Ghasemi, H. Azizi, M. Karrabi and M. Seyedabadi, Carbohydr. Polym., 2016, 144, 254-262.

50 M. Evstatiev, S. Simeonova, K. Friedrich, X. Q. Pei and P. Formanek, J. Mater. Sci., 2013, 48, 6312-6330.

51 K. I. Ku Marsilla and C. J. R. Verbeek, Eur. Polym. J., 2015, 67, 213-223.

52 G. Stoclet, R. Seguela, J. M. Lefebvre and C. Rochas, Macromolecules, 2010, 43, 7228-7237.

53 M. D. Failla and L. Mandelkern, Macromolecules, 1993, 26, 7167-7175.

54 M. A. Kennedy, A. J. Peacock and L. Mandelkern, Macromolecules, 1994, 27, 5297-5310.
55 E. Cranston, J. Kawada, S. Raymond, F. G. Morin and R. H. Marchessault, Biomacromolecules, 2003, 4, 995-999.

56 X. Q. Shi, H. Ito and T. Kikutani, Polymer, 2005, 46, 1144211450.

57 K. J. Song, J. Appl. Polym. Sci., 2000, 78, 412-423.

58 Z. Bartczak and E. Lezak, Polymer, 2005, 46, 6050-6063.

59 A. D. Jenkins, F. J. Baltá-Calleja and C. G. Vonk, X-ray scattering of synthetic polymers, Elsevier, Amsterdem, 1989.

60 O. Glatter and O. Kratky, Small angle X-ray scattering, Academic press, New York, 1982.

61 J. V. Dawkins, Developments in polymer characterization-1, Applied Science, London, 1978.

62 Y. T. Wang, Z. Y. Jiang, L. L. Fu, Y. Lu and Y. F. Men, PLoS One, 2014, 9, e97234.

63 A. Mahendrasingama, D. J. Blundella, M. Partona, A. K. Wright, J. Rasburn, T. Narayanan and W. Fuller, Polymer, 2005, 46, 6009-6015.

64 Z. Y. Jiang, L. L. Fu, Y. Y. Sun, X. H. Li and Y. F. Men, Macromolecules, 2011, 44, 7062-7065.

65 H. M. Yan, J. R. Xu, K. C. Mai and H. M. Zeng, Polymer, 1999, 40, 4865-4875. 